\title{
Turismo Cultural e Arqueologia nos espaços urbanos: caminhos para a preservação do patrimônio cultural
}

\section{Cultural Tourism and Archaeological in urban areas: paths to the preservation of cultural heritage}

\author{
Karoliny Diniz Carvalho (CARVALHO, K. D.) ${ }^{*}$
}

\begin{abstract}
RESUMO - O presente artigo busca analisar a relação entre Turismo e Arqueologia e suas contribuições para a difusão e preservação do patrimônio cultural. Nesse contexto, o estudo apresenta uma breve discussão sobre espaço urbano (SIVIEIRO, 2006) e memória (LE GOFF, 1996; BOSI, 1994), refletindo sobre a educação patrimonial (HORTA et al., 1999) e a interpretação do patrimônio (MURTA e ALBANO, 2002; COSTA, 2009) como instrumentos de valorização da cultura local. A partir da realização de uma pesquisa bibliográfica (DENCKER, 1998; MINAYO, 1999), o estudo aponta para a necessidade de se ampliar a participação da Arqueologia no planejamento da oferta do Turismo Cultural, visando à promoção da sustentabilidade nos espaços urbanos.
\end{abstract}

Palavras-chave: Turismo Cultural; Arqueologia; Patrimônio Cultural; Educação e Interpretação Patrimonial.

ABSTRACT - This paper analyzes the relationship between Tourism and Archeology and their contributions to the dissemination and preservation of cultural heritage. In this context, the study presents a brief discussion of urban space (SIVIEIRO, 2006) and memory (LE GOFF, 1996; BOSI, 1994), reflecting on the heritage education (HORTA et al., 1999) and interpretation of heritage (MURTA; ALBANO, 2002, COSTA, 2009) as a means of exploiting the local culture. Upon completion of a literature review (DENCKER, 1998; MINAYO, 1999), the study points to the need to increase participation of Archeology in the planning of the provision of Cultural Tourism for the promotion of sustainability in the spaces urban.

Key words: Cultural Tourism, Archeology, Cultural Heritage, Education and Interpretation Sheet.

\footnotetext{
* Bacharel em Turismo pela Universidade Federal do Maranhão (UFMA). Mestranda em Cultura e Turismo pela Universidade Estadual de Santa Cruz (UESC), Ilhéus, BA. Bolsista da Fundação de Amparo à Pesquisa do Estado da Bahia (FAPESB). Endereço: Rua Barão do Rio Branco, Quadra I, número 14, (Sítio Leal). CEP: 65045-340 - São Luís - MA (Brasil).E-mail: karol27_turismo@yahoo.com.br
} 


\section{INTRODUÇÃO}

O patrimônio cultural, enquanto reflexo e produto da dinâmica social, apresentase de forma diversificada, englobando as produções materiais e imateriais, passadas e presentes, os modos de vida, práticas e manifestações culturais que particularizam uma determinada sociedade. O conjunto desses elementos estabelece vínculos de temporalidade espaço-temporal entre os grupos sociais, contribuindo para a reconstrução e para o fortalecimento da memória e da identidade em uma determinada região.

Materializado e vivificado nos espaços urbanos, o patrimônio cultural constituise num sistema integrado e complexo de rupturas e continuidades, mudanças e transformações, adquirindo relevo no segmento do turismo cultural. No âmbito do mercado de consumo turístico, as áreas urbanas e seus elementos constituintes transformam-se em espaços de interação entre a comunidade local e grupos de visitantes.

A atividade turística redefine os usos do patrimônio, agenciando histórias, memórias e tradições, oportunizando o conhecimento sobre a diversidade das formas de expressão cultural. O aproveitamento do patrimônio cultural pelo turismo pode ser ampliado a partir da conjugação entre essa atividade e a prática arqueológica, sobretudo nas propostas de interpretação da cultura local. Essa associação torna-se oportuna, uma vez que a Arqueologia centra seu foco de análise na cultura material legada pelos antepassados, contextualizando objetos e artefatos, e inserindo-os na vida contemporânea.

Áreas patrimoniais que abrigam importantes sítios históricos podem traduzir-se em locais de apreciação e vivência de importantes traços da cultura, tanto para os membros de uma comunidade em geral, quanto para os visitantes, além de oportunizar, por meio das técnicas de educação patrimonial e interpretação do patrimônio, o conhecimento sobre o legado cultural, estimulando desse modo, ações de preservação dos bens culturais.

Com base nesse entendimento, o presente artigo tece algumas reflexões sobre a importância do Turismo Cultural e da Arqueologia nos espaços urbanos, no que concerne às estratégias de manutenção, preservação e difusão do patrimônio cultural. A 
partir da realização de uma pesquisa bibliográfica (DENCKER, 1998; MINAYO, 1999), a abordagem inicial centra-se nas relações entre espaço urbano, memória e patrimônio, de forma a analisar a importância das estruturas urbanas na configuração de um patrimônio singular, revelador da trajetória cultural dos grupos sociais e enquanto elos da memória e da identidade.

Em seguida, discute-se o lugar ocupado pela Arqueologia na oferta turísticocultural de uma localidade, apresentando as diferentes interfaces com o Turismo Cultural, bem como as oportunidades que esta aproximação oferece para a formatação de produtos turísticos capazes de agregar valor à experiência dos visitantes. Posteriormente, o artigo focaliza a educação patrimonial e a interpretação do patrimônio enquanto alternativas eficazes que objetivam a manutenção do legado cultural e a promoção de uma prática turística alicerçada nos princípios da sustentabilidade.

\section{ESPAÇO URBANO, MEMÓRIA E PATRIMÔNIO}

A diversidade da produção cultural, as simbologias, representações e imaginários conferidos pelos distintos grupos sociais e que revestem de sentido e significado a uma dada porção do território, estão no cerne das discussões sobre o conceito de espaço urbano e, por extensão, de cidade. Criação coletiva e locus privilegiado de compartilhamento das experiências humanas, o espaço urbano caracteriza-se pelo entrelaçamento do social, lugar onde se desenvolvem as ações dos agentes locais e os processos históricos e culturais de modo articulado e interdependente, sendo permeado por objetos, formas e conteúdos.

As cidades, por seu turno, surgem como a materialização do urbano, de concentração de pessoas, do desenrolar de atividades produtivas, tornando o espaço urbano dinâmico e polissêmico (SIVIEIRO, 2006). Além da disposição de elementos, tais como ruas, bairros, avenidas, caminhos e logradouros, os espaços urbanos evocam diferentes narrativas sobre o patrimônio cultural de uma determinada sociedade.

O patrimônio cultural diz respeito tanto à sua construção física - prédios, monumentos, edificações, acervos arquitetônicos - quanto à dimensão simbólica das diversas formas de agir, sentir e viver dos grupos sociais enquanto membros partícipes 
de uma comunidade: os ofícios e manifestações populares tradicionais, a gastronomia, as artes populares, $\mathrm{o}$ artesanato.

É nesse sentido que autores como Meneses (2004) e Pesavento (2002) compreendem os espaços urbanos como monumentos e documentos, ou seja, estes afiguram-se como suportes da identidade, em virtude das reminiscências, do simbolismo, e de sua capacidade de evocar sentidos, vivências e valores. Essa visão é compartilhada por Grammont e Moura (2006) ao analisarem a relação entre patrimônio e memória.

A memória atua no nível intersubjetivo como um quadro de referências que permite aos indivíduos perceberem nos marcos citadinos, na arquitetura e na paisagem urbana, os elementos construtores e constituintes de uma trama social comum, de uma história coletiva, cujos ecos do passado e da cultura compartilhada formam a memória social, e tem ressonância nas redes de relacionamento em geral, e nas vivências cotidianas de cada indivíduo em particular (LE GOFF, 1996; BOSI, 1994).

A partir desse entendimento, as áreas urbanas caracterizam-se por serem lugares antropológicos, em virtude da permanência de elementos materiais e imateriais a partir dos quais uma comunidade se representa simbolicamente e se individualiza. Através das feições urbanísticas, dos monumentos, casarões e prédios históricos, compreendem-se as relações sociais que ali se encerram, ou seja, as experiências coletivas e pessoais que definem o envolvimento subjetivo entre o homem e o meio ambiente físico, por um lado, e do outro, entre o homem e a identidade:

O patrimônio é uma das partes mais visíveis da memória coletiva de uma sociedade, história materializada em objetos e em ações carregadas de significados; são símbolos que, continuamente, lembram que a realidade dos processos socioculturais atuais está no passado e se articula constantemente com ele, ao redefini-lo e redefinir-se ao mesmo tempo (DIAS, 2006, p. 100).

Dessa forma, o patrimônio edificado oferece aos viventes a possibilidade de perceberem a sua origem, a de seus familiares e antepassados, ou seja, o patrimônio como representação da memória vincula os indivíduos a experiências pessoais marcantes e indeléveis que caracterizam a sua trajetória de vida. "No decorrer de sua história, toda cidade se enriquece de lugares aos quais pode ser atribuída uma função simbólica, recebida por destinação, ou em virtude de algum acontecimento" (BALANDIER, 1980, p. 11). 
Assim, os espaços urbanos não podem ser apreendidos apenas como a síntese de processos sociais e culturais, de traços remanescentes de um passado compartilhado pelo agrupamento social, e sim enquanto símbolos reveladores de práticas cotidianas, do congraçamento popular e entrelaçamento de vivências coletivas, festas, rituais e outros mecanismos de reposição de uma identidade em permanente processo de transformação.

Esse conjunto de elementos que enaltecem e reforçam o sentido do lugar (YÁZIGI, 2004), tornam-se recursos agenciados pelo mercado de consumo turístico. Essa atividade oportuniza ou amplia as estratégias de visibilidade às diferentes produções culturais, presentes ou passadas, as quais se materializam e se recriam permanentemente na dinâmica das relações sociais.

Para além dos constructos patrimoniais, observa-se que os referenciais da memória e da identidade dos diferentes grupos sociais também se encontram preservados por meio de objetos, coleções e, em alguns casos, sob a forma de importantes sítios arqueológicos presentes nas áreas urbanas. Diante dessa constatação é que se pretende refletir sobre a crescente associação entre o Turismo Cultural e a Arqueologia na preservação e disseminação do patrimônio cultural no contexto urbano.

\section{TURISMO CULTURAL E ARQUEOLOGIA: ONDE SE ENCONTRAM}

Na contemporaneidade, o patrimônio cultural vem adquirindo relevância no cenário econômico, sendo utilizado como recurso possível para alavancar o desenvolvimento sócio-econômico em diversas regiões, sobretudo por intermédio da atividade turística. Enquanto prática econômica e fenômeno social, o turismo apresenta múltiplas possibilidades de consumo dos lugares, variando de acordo com as preferências intrínsecas de cada grupo de visitantes e das vivências que estes elegem como prioritárias durante o seu período de lazer (YÚDICE, 2004).

Na visão de Barretto (2001) e Beni (2002), o Turismo Cultural pode ser entendido como o segmento da atividade no qual o interesse pela cultura torna-se a principal motivação das viagens, ou seja, o desejo de entrar em contato com as diversas formas de representação identitária e da memória étnica de uma dada comunidade

Turismo \& Sociedade, Curitiba, v. 3, n.1, p. 51-67, abril de 2010 
(festas e danças típicas, gastronomia, eventos populares tradicionais, rituais, celebrações, modos de vida).

Goulart e Santos (1998) analisam o Turismo Cultural a partir das repercussões positivas da atividade no que tange à compreensão intercultural, e das possibilidades de aprendizado que advém do processo de visitação. Costa (2009, p. 190) por sua vez, amplia as definições acerca do Turismo Cultural, sintetizando suas características sob o enfoque da oferta e da demanda, e ressaltando a importância da mediação no processo de facilitação da compreensão intercultural:

\begin{abstract}
O turismo cultural pode ser compreendido como um segmento da atividade turística que, por meio da apreciação, da vivência e da experimentação direta dos bens do patrimônio cultural, material e imaterial, e da mediação da comunicação interpretativa, proporciona aos visitantes a participação em um processo ativo de construção de conhecimentos sobre o patrimônio cultural e sobre seu contexto sócio-histórico. Em última escala, este processo auxiliará na produção de novos conhecimentos e a conservação dos bens visitados.
\end{abstract}

No campo de abrangência do Turismo Cultural insere-se o Turismo Étnico, o Gastronômico, o Religioso, entre outros, além de uma diversidade de experiências passíveis de serem realizadas pelos visitantes durante a sua permanência em um dado destino. Com o maior desenvolvimento e integração das sociedades e a ampliação do conceito de patrimônio, o Turismo Cultural foi assumindo novos contornos, adquirindo um viés integrador, uma vez que esse segmento, ao possibilitar o contato dos visitantes com a herança cultural reelaborada no cotidiano de comunidades específicas, contribui para a difusão das culturas e para uma maior compreensão intercultural (ALFONSO, 2003).

Em se tratando da prática turística nos espaços urbanos, a atividade contribui para o processo de revalorização do patrimônio cultural, por meio do estímulo à implantação de projetos e ações de revitalização que tencionam a sua incorporação à dinâmica contemporânea, e do aumento da percepção dos moradores sobre a importância da história, da cultura e das tradições enquanto elementos de reafirmação da identidade local.

Conforme observa Urry (1996), o olhar do turista direciona-se aos aspectos extraordinários do destino turístico, ou seja, os visitantes buscam apreciar as singularidades ou especificidades existentes nos valores, costumes, estilos de vida e manifestações populares que se diferenciam do seu cotidiano. Sendo o turismo uma Turismo \& Sociedade, Curitiba, v. 3, n.1, p. 51-67, abril de 2010 
atividade que necessita dos testemunhos da cultura material e intangível para a formatação de roteiros, produtos e atrações, isto é, para a configuração de um produto competitivo no mercado de consumo, emerge um vínculo estreito entre patrimônio cultural, turismo e arqueologia.

Enquanto ciência social, a Arqueologia toma como objeto de investigação a cultura material produzida pelos indivíduos em um espaço e período de tempo determinados, no sentido de revelar a complexa estrutura das relações sociais e possibilitar a compreensão das transformações pelas quais passam as sociedades ao longo do tempo.

Parte-se de uma visão semiótica da cultura seguindo os apontamentos de Geertz (1997) de que os grupos sociais são seres simbólicos e a sua produção cultural apresenta valores, sentidos e significados que só podem ser compreendidos a partir da lógica do sistema cultural que a determina e que ao mesmo tempo é determinado por ela. Ao identificar e analisar os testemunhos e traços culturais de um período histórico específico, a Arqueologia permite a reconstrução dos sistemas de representação simbólica de uma sociedade.

A diversidade dos vestígios arqueológicos depositados nas tessituras urbanas permite compreender as diferentes formas de organização do corpus social, as práticas econômicas e culturais a elas subjacentes; os significados atribuídos aos artefatos ao longo dos processos sociais, a delimitação de fronteiras étnicas e culturais entre os indivíduos pertencentes a um dado sistema cultural, dentre outras vertentes de análise e interpretação do cotidiano e das experiências humanas.

Nesse patamar, adota-se uma concepção holística e integrada da cidade e dos seus componentes, na qual as estruturas e os marcos urbanos assumem um caráter de interdependência e evocam diferentes narrativas sobre o patrimônio cultural. A Arqueologia revela a cidade como um espaço multicultural, onde se sobressaem a variedade das produções humanas e as diferentes memórias, individuais e coletivas, que dão sentido e significado à vida social:

[...] numa perspectiva relacional entre os espaços, os monumentos e os vestígios quase invisíveis, ocultos. Uma abordagem interpretativa sobre a cidade deve partir da idéia de que as diferentes manifestações arqueológicas são inter-relacionadas ao processo dinâmico que constitui a vida urbana (TOCHETTO; THIESEN, 2007, p. 179). 
A Arqueologia propicia a contextualização da vida urbana em suas diversas formas de expressão, contribuindo para o gerenciamento, preservação e difusão do patrimônio cultural, por exemplo, através da participação de arqueólogos nos programas de revitalização dos centros históricos, nos projetos de intervenção urbana, ou no processo de planejamento das cidades visando o atendimento das necessidades locais.

Vincula-se a isso o potencial sócio-educativo implícito nos remanescentes arqueológicos, uma vez que o foco de atuação da Arqueologia, especificamente da Arqueologia Pública, não se limita somente à realização de atividades de prospecção, diagnóstico e análises dos artefatos arqueológicos, convergindo para o repasse ou a transmissão dos conhecimentos produzidos para uma determinada comunidade, mediante práticas educacionais:

A arqueologia encarada como instrumento de promoção cultural e de educação pública, seus achados são ativamente difundidos em obras de divulgação científica através de exposições em museus. Parte da tarefa da arqueologia é enriquecer a compreensão das origens e da história (TRIGGER, 2004, p. 201).

Nesse patamar, as técnicas do saber e da interpretação arqueológicas contribuem para a incorporação dos vestígios da cultura material pretérita à vida contemporânea. Considera-se que a Arqueologia Pública, ao produzir conhecimento sobre o passado relacionando-o ao presente, oportuniza aos contemporâneos um importante aprendizado sobre a sua própria trajetória cultural, revigorando, assim, a importância dos referenciais culturais para o equilíbrio identitário de uma sociedade.

$\mathrm{Na}$ medida em que os artefatos arqueológicos se constituem em elementos problematizadores da vida e do cotidiano das culturas, estes podem se configurar como elementos suscitadores da visitação turística, ampliando ou fortalecendo o conjunto de atrativos comercializados em um destino e, sobretudo, serem utilizados como suportes para ações de educação patrimonial direcionadas aos membros de uma comunidade.

A Arqueologia desempenha uma importante função social nos projetos de restauração de prédios e edificações históricas, bem como na revitalização de cidades, vilas e povoados, identificando e divulgando aspectos da memória étnica e cultural dos povos que ali se estabeleceram e que contribuíram para a configuração de um espaço singular: 
A preservação desses complexos os torna excepcionalmente didáticos para a sua utilização no turismo cultural, visto que a organização da funcionalidade do espaço no passado é reveladora de muitos aspectos da vida cotidiana em vários períodos da história (PIRES, 2001, p. 12).

Estratégias de tematização da oferta turística - ambientação de fatos históricos ou a apresentação de eventos e performances culturais em áreas de interesse patrimonial - quando associadas às pesquisas arqueológicas, geram um efeito positivo no público espectador, na medida em que conferem maior autenticidade às atrações apresentadas, além de contribuir para a transformação dos espaços urbanos em locais de intercâmbio cultural e de aprendizado.

Museus, centros culturais e demais locais de salvaguarda e exposição do patrimônio cultural podem ampliar seu potencial de atratividade ao intensificarem seu interesse pelos objetos e artefatos resultantes da investigação arqueológica. Exposições museológicas diversificadas que ressaltem a plurietnicidade $\mathrm{e}$ as diferentes representações da cultura local tendem a ampliar o papel do Turismo e da Arqueologia na preservação do patrimônio, ao tempo em que reforçam o direito à memória e à cidadania cultural.

Outro aspecto a ser destacado refere-se à formatação de produtos turísticos e culturais específicos, segmento do Turismo Cultural denominado Turismo Arqueológico ou Arqueoturismo. Esta modalidade enfatiza a vivência dos turistas em áreas de importância arqueológica e que detém um significado espiritual ou simbólico para as comunidades, por meio da observação ou do desenvolvimento de atividades práticas em escavações parciais de sítios históricos ou pré-históricos (MANZATO, 2007).

No Brasil, destacam-se experiências exitosas em sítios arqueológicos como demonstra a gestão do Parque Nacional da Serra da Capivara no Estado do Piauí (PI), e que vinculam o turismo e a prática arqueológica como instrumentos de promoção e preservação do patrimônio cultural. Existem ainda roteiros e itinerários que promovem a interação dos visitantes com o meio ambiente, a gastronomia e os remanescentes arqueológicos de grupos sociais construtores do lugar turístico, agregando valor à oferta do turismo cultural.

Observa-se que nessa modalidade de turismo, não apenas os remanescentes ou referenciais da cultura material tornam-se importantes recursos ou atrativos turísticos, 
mas, sobretudo a paisagem, a tradição oral, os imaginários e as histórias construídos sobre o lugar contribuem para a conformação de uma experiência significativa para os visitantes, objetivo maior do turismo com base no legado cultural (BRUM, 2007; MACHADO et al., 2009; BARRETTO, 2001).

Diante do exposto, a visitação turística nos espaços urbanos amplia as possibilidades de preservação e valorização do patrimônio cultural. Entretanto, faz-se necessária uma atuação interdisciplinar no processo de gestão e comercialização dos bens culturais, enquanto elementos propulsores do turismo.

O aproveitamento turístico do patrimônio cultural deve estar associado a atividades educativas que oportunizem a apropriação e a valorização do legado cultural pela comunidade, mediante a interpretação dos vestígios da cultura material produzida em diferentes épocas e contextos históricos. Nesse sentido, a busca por uma maior aproximação entre a Arqueologia e o planejamento da oferta turística pode contribuir para a promoção da sustentabilidade do patrimônio cultural, e para o desenvolvimento socioeconômico local.

\section{EDUCAÇÃo E INTERPRETAÇÃO PATRIMONIAL: PROMOVENDO A SUSTENTABILIDADE DO PATRIMÔNIO}

Os espaços urbanos, sobretudo os locais de valor histórico e cultural, devem ser vistos como áreas a serem descobertas e, portanto, compreendidas pelos turistas e pela comunidade local através de elementos interpretativos que possam valorizar a sua identidade, suas histórias, os aspectos arquitetônicos, os valores artísticos tradicionais e a sua importância cultural.

Segundo Camargo (2002), para que haja o pleno desenvolvimento do Turismo Cultural a população residente enquanto agente produtora do patrimônio deve ser conscientizada sobre a importância dos bens culturais enquanto suportes de memória, de continuidade de práticas sócio-culturais e vetores de desenvolvimento econômico.

Nesse contexto, o saber-fazer arqueológico confere maior visibilidade ao legado cultural e às produções coletivas, reforçando as singularidades dos elementos que integram os espaços urbanos - monumentos, edificações históricas, logradouros, 
práticas e manifestações sócio-culturais - ao tempo em que amplia a percepção da cidade como lócus de criação coletiva, dinâmica e mutável.

O planejamento da oferta cultural deve priorizar um diálogo mais estreito com a Arqueologia, notadamente no que se refere à necessidade de se promover a sustentabilidade no turismo. Para o alcance da sustentabilidade, devem ser consideradas as dimensões econômica, social, ecológica e espacial (SACHS, 1994), as quais permitem um desenvolvimento equilibrado dessa atividade.

O conceito de sustentabilidade aplicado ao turismo apresenta um conjunto de dimensões (social, ambiental, cultural, econômica, tecnológica), e deve promover a integralidade do meio ambiente físico e cultural, a inserção da comunidade aos benefícios gerados pelo turismo, e a otimização da experiência dos visitantes. Reportando-se à cultura, segundo Rodríguez (1997, p. 58):

A dimensão cultural busca nas raízes endógenas, a diversidade e a pluralidade cultural, pela preservação do patrimônio, dos recursos culturais em respeito aos modelos autóctones. Através da capacidade de autogestão das comunidades locais, participando na tomada de decisões, procura sistemas alternativos de tecnologia e produção.

O envolvimento da comunidade local na preservação dos bens culturais e a sua incorporação à atividade turística emergem como requisitos necessários "à obtenção de modelos turísticos integrados à economia e à sociedade que respeitem o patrimônio arquitetônico e o meio ambiente e que se preocupem com as novas demandas de acessibilidade e mobilidade que o turismo propõe" (VINUESA, 2004, p. 35).

Na esfera da gestão do patrimônio cultural, a Arqueologia Pública possibilita a manutenção das características particulares dos sítios históricos, evitando ou minimizando as ingerências negativas da visitação em áreas de interesse patrimonial. Além de disseminar informações e conhecimentos sobre o patrimônio, a Arqueologia oferece subsídios para o fortalecimento da memória e da identidade local, contribuindo para a revitalização dos marcos urbanos por meio da sua transformação em atrações turísticas, e estimulando benefícios para a população local.

Por intermédio de atividades de educação e interpretação patrimonial, a ciência arqueológica estimula o sentimento de pertença da comunidade em relação aos bens 
culturais e, por extensão, o seu envolvimento na preservação dos elementos representativos de sua memória e identidade.

Na visão de Machado et al. ( 2009, p. 579):

\begin{abstract}
As relações tempo- espaciais, possibilitadas pela história, os traços culturais específicos revelados pela cultura material e as evoluções técnicas espontâneas ou pré-determinadas emanadas da arquitetura, possibilitarão ao produto turístico ultrapassar a unilateralidade econômica, acentuando no agente dessa área a potencialidade comunicativa da preservação.
\end{abstract}

Entende-se a educação patrimonial como um processo sócio-educativo que permite a descoberta, o reconhecimento e a valorização dos significados históricos, culturais e simbólicos dos bens materiais ou espirituais produzidos pelos diversos grupos sociais em contextos específicos (HORTA et al., 1999). Utilizando-se de diferentes suportes de memória - monumentos e prédios históricos, conjuntos arquitetônicos, sítios arqueológicos, vestimentas - a educação patrimonial desperta sensibilidades e desenvolve o senso de preservação do legado cultural no interior das comunidades.

A educação patrimonial possibilita ainda a transformação do morador em turista cidadão (MOESCH, 2005), na medida em que estimula na população residente o desejo de redescobrir a cidade e suas relações, de resgatar seus aspectos históricos, culturais, ambientais e turísticos, contribuindo para a formação da cidadania e para o fortalecimento do sentimento de afetividade e de apreço ao lugar:

O turista cidadão é aquele morador da localidade que vivencia práticas sociais, no seu tempo rotineiro, dentro de sua cidade, de forma não rotineira, onde é provado em relação à cidade. Turista cidadão é aquele que resgata a cultura de sua cidade fazendo uso do estranhamento da mesma. Este estranhamento inicia no momento em que o indivíduo descobre no espaço cotidiano outras culturas, outras formas étnicas e outras oportunidades de lazer e entretenimento. Quando se encontra na situação de turista cidadão, este sujeito aprende a utilizar os espaços ambientais, culturais, históricos, comerciais e de entretenimento com uma percepção diferenciada de seu cotidiano (MOESCH, 2005 apud SALES, 2006, p. 117). ${ }^{1}$

A partir do autoconhecimento e compreensão do próprio lugar podem-se desenvolver políticas preservacionistas mais eficazes, além de diferenciar e melhor

\footnotetext{
${ }^{1}$ Informação disponibilizada em mensagem eletrônica. A título de ilustração, ver Sales (2006) nas referências listadas ao final do artigo.
}

Turismo \& Sociedade, Curitiba, v. 3, n.1, p. 51-67, abril de 2010 
aproveitar o patrimônio enquanto atração turística. Nesse sentido, amplia-se o significado do legado cultural nos contextos urbanos enquanto suportes de memória e identidade, vinculando os significados aos objetos arregimentados e problematizando o seu conteúdo.

Considerada um processo social que desvela os valores históricos, arquitetônicos e culturais, os sentidos e significados dos espaços urbanos para a comunidade e para grupos de visitantes, a interpretação do patrimônio constitui-se num importante instrumento destinado ao resgate e à valorização da história e da memória local, dos marcos referenciais e simbólicos presentes na cidade e, sobretudo, de intensificação dos vínculos de afetividade e de compromisso dos moradores com o patrimônio do lugar (MURTA; ALBANO, 2002).

Por intermédio de instrumentos de valorização e apropriação dos bens culturais, tais como trilhas interpretativas, painéis e placas de sinalização e comunicação, mídia, a comunidade pode sentir-se integrada aos espaços urbanos, valorizando os bens culturais testemunhos de sua história e identidade. O aproveitamento do patrimônio cultural pela atividade turística deve considerar os elementos definidores da cultura sob o olhar da comunidade, incrementando a oferta local com roteiros, serviços e produtos que enalteçam a vivência dos turistas no destino, além de enfatizar o protagonismo da comunidade em áreas de interesse turístico. Assim, o turismo será entendido como instrumento de reforço das identidades e de articulação das culturas locais, ao estimular a participação da comunidade no processo de planejamento e gestão da oferta turística.

A adequada interpretação do patrimônio permite maximizar as potencialidades do meio-ambiente natural e cultural através de uma metodologia que identifique os atrativos e sua importância, e estabeleça as relações entre os fatos históricos que os circunscrevem e a sociedade atual. Fornece ainda aos visitantes uma experiência particular, agregando valor às características e peculiaridades da cultura, mediante uma proposta didático-pedagógica que permite o estabelecimento de um vínculo estreito entre o patrimônio e os moradores e, consequentemente, entre estes e os turistas.

É o que assinala Costa (2009, p. 190):

Transformar a motivação cultural das viagens, de um cenário onde se realizam visitas de pessoas em busca de alteração temporária em seu espaço e tempo cotidianos para um cenário político-cultural, no qual os visitantes e residentes interagem com sua cultura ou com a de seu semelhante, em que as 
pessoas aprendem o significado de seu passado: essa é a mudança que se propõe realizar com a instrumentalização da interpretação nas visitas aos sítios patrimoniais por meio do turismo cultural.

Além de proporcionar a valorização dos atrativos naturais e culturais pelos membros de uma coletividade, a interpretação do patrimônio propicia a sustentabilidade financeiro-econômica para as comunidades locais decorrente do processo de visitação. Enfatiza-se que a interpretação está ancorada nas expectativas, anseios e necessidades da população local, criando possibilidades efetivas de inserção social em áreas ligadas direta ou indiretamente ao turismo, de modo a garantir que a mesma tenha acesso aos benefícios proporcionados pela atividade.

\section{CONSIDERAÇÕES FINAIS}

Os espaços urbanos afiguram-se como importantes testemunhos das experiências individuais e coletivas em um dado momento histórico, presente e passado, materializando a dimensão simbólica das diversas formas de agir, sentir e viver em sociedade. O patrimônio cultural herdado e recriado no corpus social é visto também como elemento de atratividade turística, estimulando fluxos de visitantes e, com eles, oportunidades de preservação cultural e geração de benefícios sócio-econômicos para as comunidades.

A vivência dos turistas com os referenciais da memória e da identidade de um lugar pressupõe a utilização de instrumentos que possam contribuir para a sustentabilidade do Turismo Cultural. Nesse patamar, busca-se ampliar o diálogo entre Turismo e Arqueologia, uma vez que o saber-fazer arqueológico pode contribuir não apenas para ampliar a oferta de atrativos turísticos de uma localidade, mas, sobretudo, para estimular ações de permanência e difusão dos bens culturais.

Nesse sentido, constata-se que a educação patrimonial e a implantação de um sistema de comunicação interpretativa visando mediar à relação entre turistas, comunidades e bens culturais, tornam-se alternativas capazes de proporcionar novos sentidos e significados aos espaços urbanos, enaltecendo seus elementos e estimulando ações preservacionistas. 
O Turismo Cultural e a Arqueologia tendem, pois, a fortalecer os laços de afetividade entre a população local e o seu patrimônio, ao tempo em que promovem a sua contextualização para o público visitante. Atrela-se a esse fato a questão da sustentabilidade, posto que tais práticas revelam um interesse sócio-educativo nas visitas aos espaços de memória e identidade, além de propiciar o envolvimento da população local no processo de valorização dos bens culturais.

\section{REFERÊNCIAS}

ALFONSO, M. J. P. El Patrimonio Cultural como Opción Turística. In: Horizontes Antropológicos, Porto Alegre, ano 9, n. 20, p. 97-115, outubro de 2003.

BALANDIER, G. O poder em cena. Brasília: Universidade de Brasília, 1980.

BARRETTO, M. Turismo e legado cultural. As possibilidades de planejamento. São Paulo: Papirus, 2001.

BENI, M. C. Análise Estrutural do Turismo. São Paulo: Roca, 2002.

BOSI, E. Memória e sociedade: lembranças de velhos. São Paulo: Companhia das Letras, 1994.

BRUM, C. K. Turismo, Arqueologia e Literatura: Análise antropológica da construção da memória coletiva em São Nicolau/RS. Revista Brasileira de Pesquisa em Turismo, v. 1, n. 1, p. 54-83, Set. 2007.

CAMARGO, H. L. Patrimônio Histórico e Cultural. São Paulo: Aleph, 2002.

COSTA, F. R. Turismo e patrimônio cultural: interpretação e qualificação. São Paulo: SENAC, 2009.

DENCKER, A. de F. M. Métodos e técnicas de pesquisa em turismo. São Paulo: Futura, 1998.

DIAS, R. Turismo e patrimônio cultural: recursos que acompanham o crescimento das cidades. São Paulo: Saraiva, 2006.

GOULART, M.; SANTOS, R. I. C. Uma abordagem histórico-cultural do turismo. Turismo - Visão e Ação, v. 1, n. 1, p. 19-28, jan./jun. 1998.

GEERTZ, C. O saber local: novos ensaios em antropologia interpretativa. Petrópolis, RJ: Vozes, 1997. 
GRAMMONT, A. M. de; MOURA, M. A. Os significados do Patrimônio Histórico: uma reflexão em torno do caso do casarão incendiado em Ouro Preto. In: SALVADOR, D. P. T. (Org.) e colaboradores. Comunidades Sustentáveis: a partir do turismo com base local. Ilhéus: Editus, 2006.

HORTA, M. de L. P.; GRUNBERG, E.; MONTEIRO, A. Q. Guia básico de educação patrimonial. Brasília: IPHAN, Museu Imperial, 1999.

LE GOFF, J. História e Memória. Campinas: Unicamp, 1996.

MACHADO, N. T. G.; LOPES, S. N.; GHENO, D. A. Arqueologia Histórica e a Problemática do Patrimônio: discussões acerca da preservação, turismo e educação patrimonial no Vale do Taquari - Rio Grande do Sul. In: O Vale do Taquari - Rio Grande do Sul. História, v. 28, n. 1, p. 575-588, 2009.

MANZATO, F. Turismo Arqueológico: diagnóstico e análise do produto arqueoturístico. In: PASOS. Revista Eletrônica de Turismo e Patrimônio Cultural, v. 5, n. 1, 2007, p. 99-109. Disponível em: <http://www.pasosonline.org.>. Acesso em: novembro de 2009.

MENESES, J. N. C. História e Turismo Cultural. Belo Horizonte: Autêntica, 2004

MINAYO, M. de S. O desafio do conhecimento: pesquisa qualitativa em saúde. São Paulo: Hucitec; Rio de Janeiro: Abrasco, 1999.

MOESCH. M. Turista cidadão. Informação disponibilizada em mensagem eletrônica. In: SALES, F. de L. Educação Patrimonial e o Turismo: o caso do Programa de Educação Patrimonial do Museu Municipal de Caxias do Sul - RS. 154 f. Dissertação (Mestrado Acadêmico em Turismo) - Universidade de Caxias do Sul. Caxias do Sul, 2006.

MURTA, S. M.; ALBANO, C. (Orgs.). Interpretar o patrimônio: um exercício do olhar. Belo Horizonte: Ed UFMG, 2002.

PESAVENTO, S. J. Memória, História e Cidade: lugares no tempo, momentos no espaço. In: Universidade Federal de Uberlândia. Revista do NEHAC - Núcleo de Estudo em História Social da Arte e da Cultura, n.4, v. 4, p. 23-35, 2002.

PIRES, M. J. Lazer e Turismo Cultural. São Paulo: Manole, 2001.

RODRIGUÉZ, J. M. M. Desenvolvimento Sustentável: níveis conceituais e modelos. In: CAVALCANTI, A. P. B. (Org.). Desenvolvimento Sustentável e planejamento: bases teóricas e conceituais. Fortaleza: UFC- Imprensa Universitária, 1997.

SACHS, I. Estratégias de transição para o século XXI. Desenvolvimento e meio ambiente. São Paulo: Nobel, 1994. 
SALES, F. de L. Educação Patrimonial e o Turismo: o caso do Programa de Educação Patrimonial do Museu Municipal de Caxias do Sul - RS. 154 f. Dissertação (Mestrado Acadêmico em Turismo) - Universidade de Caxias do Sul. Caxias do Sul, 2006.

SIVIEIRO, A. P. Os elementos do espaço turístico urbano no processo de planejamento: reflexões teóricas e articulações. In: R. RA'EGA, Curitiba, n. 11, p. 51-59, Editora UFPR, 2006.

TOCHETTO, F.; THIESEN, B. A memória fora de nós: a preservação do patrimônio arqueológico em áreas urbanas. In: Revista do Patrimônio Histórico e Artístico Nacional. Patrimônio Arqueológico: o desafio da preservação. Brasília, n. 33, p. 175201, 2007.

TRIGGER, B. G. A História do Pensamento Arqueológico. São Paulo: Ed. Odysseus, 2004.

URRY, J. O olhar do turista: lazer e viagens nas sociedades contemporâneas. São Paulo: EDUSC, 1996.

VINUESA, M. A. T. Turismo e desenvolvimento nas cidades históricas IberoAmericanas: desafios e oportunidades. In: PORTUGUEZ, A. P. (Org.). Turismo Memória e Patrimônio Cultural. São Paulo: Roca, 2004.

YÁSIGI, E. A alma do lugar: Turismo, planejamento e cotidiano. São Paulo: Contexto, 2001.

YÚDICE, G. A conveniência da cultura: usos da cultura na era global. Belo Horizonte: UFMG, 2004.

Recebido em: 25/01/2010

Aprovado em: 25/02/2010 